UDK: 005.62:502

DOI: https://doi.org/10.24867/07GI13Pecic

\title{
SISTEM MENADŽMENTA ŽIVOTNOM SREDINOM KAO OSNOVA ZA REŠAVANJE PROBLEMA NEADEKVATNOG UPRAVLJANJA OPASNIM OTPADOM
}

\section{ENVIRONMENTAL MANAGEMENT SYSTEM AS A BASIS OF SOLVING THE PROBLEM OF INADEQUATE MANAGEMENT OF HAZARDOUS WASTE}

Jelena Pecić, Fakultet tehničkih nauka, Novi Sad

\section{Oblast - INDUSTRIJSKO INŽENJERSTVO I MENADŽMENT}

Kratak sadržaj - Tema ovog rada jeste upoznavanje sa problemom upravljanja otpadom, odnosno njegovim adekvatnim odlaganjem. Definisane su dve grupe predloga za rešenje predstavljenih problema - tehničkotehnološko koje obuhvata odgovarajući tretman opasnog otpada, i organizaciono koje se odnosi na implementaciju ISO 14001:2015 u cilju prevencije.

Ključne reči: Logistika, Opasan otpad, Upravljanje otpadom

\begin{abstract}
The theme of this paper is to introduce a problem of waste management and it's adequate disposal. There are representet two groups of proposals for the solution of the problems that have been defined technical, which includes the appropriate tratment of hazardous waste, and organizational, related to the implementation of ISO 14001:2015 for the purpose of prevention.
\end{abstract}

Keywords: Logistics, Hazardous Waste, Waste Management

\section{UVOD}

Predmet ovog rada jeste uspostavljanje sistema menadžmenta životnom sredinom u cilju preventivnog ali i korektivnog delovanja na neadekvatno odlaganje opasnog otpada. Ispravan pristup upravljanju otpadom obuhvata hijerarhijsko odvijanje aktivnosti. Pre svega treba težiti minimizaciji količine otpada na izvoru, sledeća jeste reciklaža otpada, zatim njegova prerada adekvatnom tehnikom, i kao krajnje rešenje deponovanje otpada [1].

Samim tim da veliki broj organizacija u Srbiji ima neadekvatno uskladišten opasan otpad, u najvećoj meri na prostoru organizacija koje su u stečaju, data su rešenja za ovu vrstu problema. Kroz tehničko-tehnološka rešenja predstavljene su mogućnosti delovanja na već postojeći problem - tretman opasnog otpada u Srbiji, i izvoz opasnog otpada u inostrantsvo kako bi se dalje tretirao na adekvatan način. Zatim kroz organizaciono rešenje, definisana je implementacija ISO 14001:2015, gde su predstavljeni aspekti uticaja na životnu sredinu, kao i načini reagovanja u slučaju pojave vanrednih situacija.

\section{NAPOMENA:}

Ovaj rad proistekao je iz master rada čiji mentor je bio dr Nebojša Brkljač, docent

\section{PRIMERI NEADEKVATNOG UPRAVLJANJA OPASNIM OTPADOM U SRBIJI}

Primeri koji su obrađeni u okviru rada, i količine opasnog otpada se odnose na organizacije koje se nalaze u stečaju, i koje su u okviru fabrike odložile i napustile velike količine opasnog otpada, i to na neadekvatan način. Samim tim da su fabrike ostale nezaštićene, bez stalnog nadzora, dolazi do čestih neovlašćenih pristupa, pa zatim i mnogobrojnih incidenata kao što su požar, curenje materija u okolinu, rušenje zgrade i slično.

Otpad koji je pronađen je klasifikovan prema Katalogu otpada [2], kako bi se utvrdila njegova svojstva, odnosno da li je u pitanju opasan otpad ili ne.

U Tabeli 1. se može videti da su sve vrste otpada označene *, što znači da spadaju u kategoriju opasnih.

Tabela 1. Klasifikacija materija na osnovu Kataloga otpada

\begin{tabular}{|c|c|}
\hline Naziv otpada & Indeksni broj otpada \\
\hline Crni lug & $060204^{*}$ \\
\hline Furfural & $040214^{*}$ \\
\hline Ugljen disulfid & $070204^{*}$ \\
\hline Cijanidna so & $060311^{*}$ \\
\hline Mazut & $130703^{*}$ \\
\hline
\end{tabular}

\subsection{Tehničko-tehnološka rešenja}

Ova vrsta rešenja obuhvata fizičko-hemijski tretman opasnog otpada. Kako bi se tretman izvršio na odgovarajući način, neophodno je pratiti zakonsku regulativu $i$ ispuniti sve tražene zahteve (najpre što se tiče dokumentacije za kretanje ali i sam tretman otpada), jer su u pitanju opasne materije koje mogu da imaju veliki broj negativnih uticaja na životnu sredinu.

Pre svega je potrebno definisati uzroke koji su doveli do problema velikih količina opasnog otpada koji je uskladišten i odložen na neadekvatan način.

U tom cilju, korišćena je metoda Ishikawa dijagram, kako bi se na slikovit način predstavili svi mogući uzroci ovog problema, koji su predstavljeni u 4 grupe, takozvane 4M: Men, Mashines, Materials, Methods, uz dodatak kategorije Resursi. Na slici 1 je predstavljen Ishikawa dijagram. 


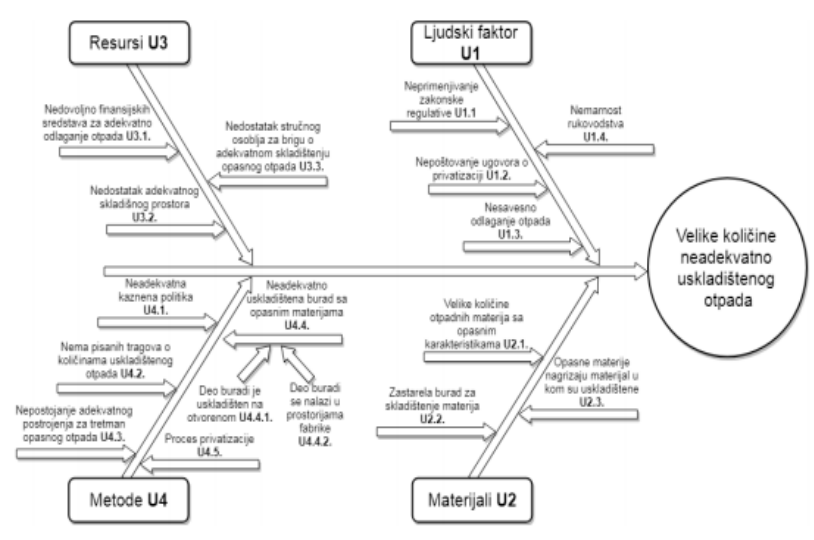

Slika 1. Ishikawa dijagram

Nakon što su svi uzroci predstavljeni, i problem je definisan i razrađen, pristupa se jednom od dva predloga za tretman, a to su:

- Tretman opasnog otpada u Srbiji,

- Tretman opasnog otpada izvozom.

Za tretman opasnog otpada u Srbiji će biti zaduženo preduzeće „Miteco Kneževac d.o.o.“, koje poseduje odgovarajuća postrojenja za tretman opasnih materija koje su predmet ovog rada. Preduzeće će u skladu sa zakonskom regulativom sprovesti zamenu ambalaže kako bi se olakšao transport, zatim transportovati materije do postrojenja, i izvršiti dalji tretman opasnih materija.

Tretman opasnog otpada izvozom se u određenoj meri razlikuje od tretmana u granicama naše zemlje, po pitanju samog postupka izvoza ali i carinjenja otpada [3]. Opasne materije će preći veliku razdaljinu do krajnjeg odredišta, te ce predstavljati pretnju za okolinu ukoliko se ne osigura bezbedan transport i mogućnost razlivanja u okolinu svede na minimum. Izvoz sprovodi specijalizovana organizacija za ovu delatnost, koja će izvršiti postupak izvoza, koji uključuje prikupljanje neophodne dokumentacije, kao i carinjenje i predaju materija organizaciji koja će izvršiti dalji tretman opasnog otpada u svom postrojenju.

Prilikom odabira bilo koja od dva predstavljena rešenja, potrebno je izvršiti zamenu ambalaže, kao i njeno obeležavanje i obeležavanje transportnog sredstva na način propisan zakonom, kako ne bi došlo do curenja materija i kako bi se znalo koje se materije transportuju.

\subsection{Organizaciono rešenje}

Organizaciono rešenje podrazumeva implementaciju ISO 14011:2015 - Sistem upravljanja zaštitom životne sredine. Ovaj standard se zasniva na kontrolisanju rizika zagađenja životne sredine, i uspostavlja mehanizme koji vremenom smanjuju ove rizike i broj incidenata i jačaju pouzdanost organizacije $u$ ispunjenju zakonskih i drugih zahteva životne sredine [4].

Za potrebe ovog rada, preuzeta je tipska procedura Zaštite životne sredine kao i procedura Upravljanja otpadom.

U okviru procedure Zaštita životne sredine je potrebno ispuniti odgovarajuće obrasce kako bi se procenio negativan uticaj na životnu sredinu, kao i moguće vanredne situacije $\mathrm{i}$ reagovanje $\mathrm{u}$ slučaju njihove realizacije.
Pre svega je predstavljena lista propisa zajedno sa zahtevima koje je potrebno ispuniti, kao i osoba koja će biti odgovorna za primenu zahteva. Identifikacija i vrednovanje aspekata životne sredine jeste tačka koja govori o tome koliki su negativni uticaji po životu sredinu što se može videti u Tabeli 2. Svi pobrojani uticaji se vrednuju, i na osnovu dobijenih rezultata, svi aspekti koji imaju zbir veći od 30 predstavljaju značajan uticaj na životnu sredinu, i na njih je potrebno obratiti posebnu pažnju kako ne bi došlo do njihove realizacije.

Tabela 2. Tabela značajnosti aspekata životne sredine

\begin{tabular}{|c|c|}
\hline ASPEKT & UTICAJ \\
\hline $\begin{array}{c}\text { Emisija štetnih gasova nastalih požarima u } \\
\text { prostorijama gde su opasne materije }\end{array}$ & Značajan \\
\hline Curenje opasnih materija & Značajan \\
\hline Neadekvatno odlaganje opasnih materija & Značajan \\
\hline Utovar ambalaže sa opasnim otpadom & Zanemarljiv \\
\hline Transport opasnog otpada & Zanemarljiv \\
\hline Istovar opasnog otpada & Zanemarljiv \\
\hline
\end{tabular}

Na osnovu identifikovanih aspekata i zakonske regulative, definišu se ciljevi životne sredine i šta se želi postići konkretnim ciljem. Uz ciljeve se definiše i program njihove realizacije gde su pobrojane aktivnosti koje je potrebno sprovesti, neophodne resurse, rok ispunjavanja kao i odgovorne osobe.

Kako uvek postoji mogućnost od realizacije vanrednih situacija, neophodno je imati definisan plan u slučaju njihove pojave, kao i postupanje kako bi se sprečila njihova realizacija. Moguće vanredne situacije $u$ fabrikama koje imaju neadekvatno odložen opasan otpad su najčešće:

- Izlivanje opasne materije,

- Oštećenje ambalaže,

- Požar izazvan curenjem opasne materije i

- Neovlašćen pristup skladištu sa opasnim materijama.

Od velike važnosti je, nakon što su napravljena sva ispitivanja u cilju saznanja koliki su uticaji po životnu sredinu, napraviti plan praćenja i merenja učinka na zaštiti životne sredine. Ovim planom se definišu parametri koji će u budućnosti biti praćeni na određeni vremenski period, gde će se svi zapisi arhivirati i koji će služiti kao primer.

Procedura Upravljanje otpadom podrazumeva definisanje liste otpadog materijala, gde se definiše da li je u pitanju opasan ili neopasan otpad, kao i detaljan opis postupanja sa konkretnim materijama. Takođe se popunjava i Izveštaj o upravljanju otpadnim materijama, gde su definisane količine materija, što se može videti na slici 2 .

\begin{tabular}{|c|c|c|}
\hline $\begin{array}{c}\text { Reani } \\
\text { broj }\end{array}$ & $\begin{array}{c}\text { NAZIV } \\
\text { OTPADNIH } \\
\text { MATERIJA }\end{array}$ & Ukupno \\
\hline 1. & Crni lug & $300 \mathrm{~m}^{3}$ \\
\hline 2. & Furfural & $20 \mathrm{~m}^{3}$ \\
\hline 3. & Ugljen disulfid & $1.500 \mathrm{~m}^{3}$ \\
\hline 4. & Cijanidna so & $75 \mathrm{t}$ \\
\hline 5. & Mazut & $15 \mathrm{t}$ \\
\hline
\end{tabular}

Slika 2. Količine opasnih materija 
Kada su definisane količine, popunjava se Godišnji izveštaj o otpadu, gde se nalaze podaci o vlasniku otpada, odgovornom licu, samom otpadu (vrste i klasifikacija, količine), kao i podaci o tome da li je bilo kretanja otpada u prethodnom periodu i na koji način.

\subsection{Gantov dijagram}

Kako bi se odredio vremenski period koji je neophodan za sprovođenje definisanih aktivnosti za tretman opasnog otpada, urađena su dva Gantograma, u okviru kojih su redom predstavljene aktivnosti za obe vrste rešenja (tretman opasnog otpada u Srbiji na slici 3 i tretman opasnog otpada izvozom na slici 4). Procenjeno vreme koje je potrebno za tretman unutar granica Srbije jeste 27 dana, dok je za izvoz potrebno oko 60 dana.

Vreme trajanja predstavljenih postupaka može da varira, u slučaju kašnjenja dokumentacije ili njenog ranijeg pristizanja, kao i u zavisnosti od samog trajanja postupka tretmana otpada.

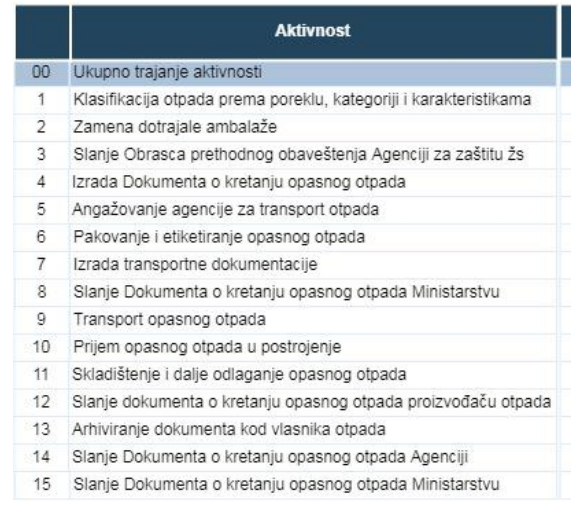

\begin{tabular}{|c|c|c|}
\hline $\begin{array}{l}\text { Trajanje } \\
\text { aktivnosti }\end{array}$ & Početak & Završetak \\
\hline 27 dana & 01.10 .19 & 06.11 .19 \\
\hline 11 dana & 01.10.19. & 15.10.19. \\
\hline 3 dana & 16.10.19. & 18.10.19. \\
\hline 1 dan & 21.10.19. & 21.10.19. \\
\hline 1 dan & 22.10.19. & 22.10.19. \\
\hline 4 dana & 15.10.19. & 18.10.19. \\
\hline 1 dan & 18.10.19. & 18.10.19. \\
\hline 2 dana & 18.10.19. & 21.10.19. \\
\hline 1 dan & 21.10.19. & 21.10.19. \\
\hline 2 dana & 23.10 .19 . & 25.10.19. \\
\hline 1 dan & 25.10.19. & 25.10 .19 \\
\hline 5 dana & 25.10 .19 . & 31.10.19. \\
\hline 4 dana & 31.10.19. & 05.11.19. \\
\hline 1 dan & 05.11.19. & 05.11.19. \\
\hline 1 dan & 06.11.19. & 06.11.19. \\
\hline 1 dan & 06.11.19. & 06.11 .19 \\
\hline
\end{tabular}

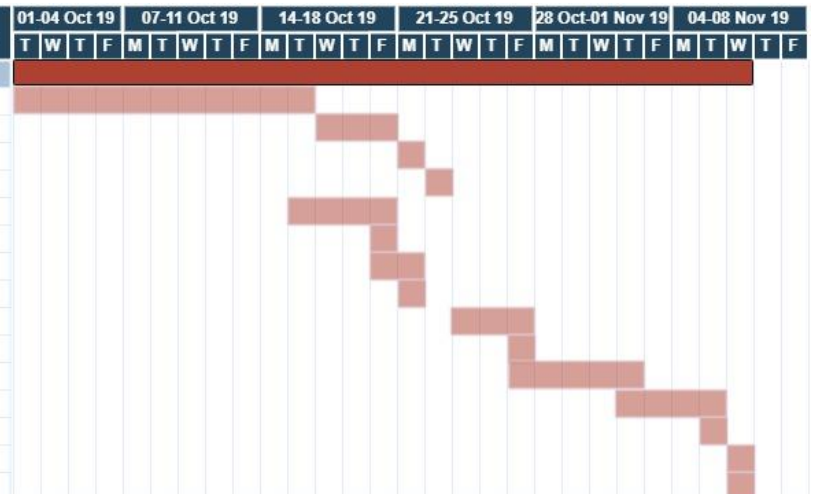

Slika 3. Gantogram tretmana opasnog otpada u Srbiji

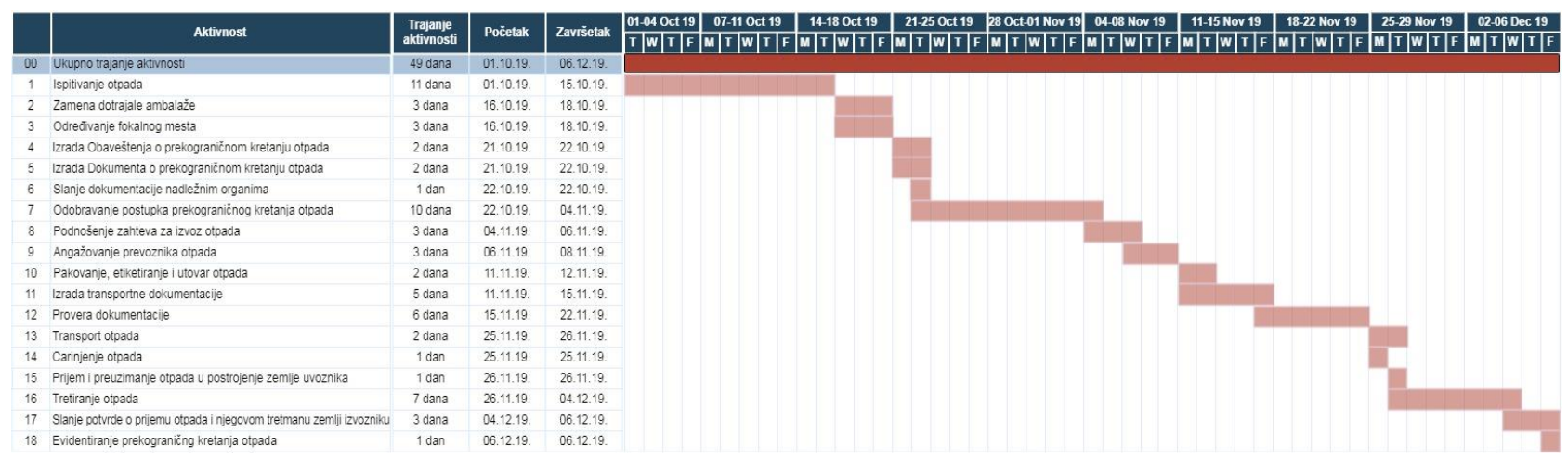

Slika 4. Gantogram tretmana opasnog otpada izvozom

\section{ZAKLJUČAK}

Samim tim da je tema upravljanja otpadom veoma važna po životnu sredinu jer ima veliki uticaj na nju, neophodno je pozabaviti se ovim problemom i preduzeti sve mere kako bi se u što većem procentu smanjio negativan uticaj.

Rešenja koja su predstavljena u radu su odgovarajuća za konkretan problem neadekvatnog odlaganja opasnog otpada i oba rešenja predstavljaju značajan pomak ka uspešnom otklanjaju problema, bilo da se on već desio ili kao prevencija.

Razlika u rešenjima jeste $\mathrm{u}$ potrebnim finansijskim sredstvima, jer je izvoz opasnog otpada finansijski zahtevniji, zbog velikog broja potrebne dokumentacije, kao i dobijanja dozvola i uplaćivanja taksi. Procena jeste da cena izvoza opasnog otpada iznosi od 1,5 do 6 evra po kilogramu otpada, što bi ukupno premašivalo i milione evra zbog velikih količina. Tretman opasnog otpada $\mathrm{u}$ Srbiji zahteva manju količinu sredstava,

\section{LITERATURA}

[1] http://www.sepa.gov.rs/index.php?menu=207\&id=202 \&akcija=showXlinked (pristupljeno u oktobru 2019.)
[2] http://www.pravnoinformacionisistem.rs/SlGlasnikPortal/eli/rep/sgrs/minista rstva/pra vilnik/2010/56/1/reg (pristupljeno u oktobru 2019.)

[3] http://www.pravno-informacionisistem.rs/SlGlasnikPortal/eli/rep/sgrs/ministarstva/praviln $\mathrm{ik/2009/60/1/reg} \mathrm{(pristupljeno} \mathrm{u} \mathrm{oktobru} \mathrm{2019.)}$

[4] http://iso.org.rs/iso14001/ (pristupljeno u oktobru 2019.)

\section{Kratka biografija:}

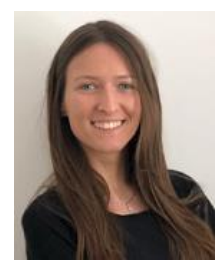

Jelena Pecić rođena je u Loznici 1995. god. Završava Srednju ekonomsku školu u Loznici. Nakon završetka Ekonomske škole, smer Finansijski tehničar, upisuje Fakultet tehničkih nauka u Novom Sadu 2014. godine. 2018. godine upisuje master studije na Katedri za kvalitet, efektivnost i logistiku. kontakt: jelena.pecic95@gmail.com 